\title{
DETERMINING THE REGIONAL POTENTIAL FOR DEVELOPMENT OF INDUSTRY 4.0
}

\author{
Ivaylo Ivanov \\ Faculty of Business Management, University of Forestry, 10 St Kliment Ohridski blvd, 1797 Sofia, Bulgaria \\ E-mail: ihivanov@hotmail.com
}

Received 31 March 2020; accepted 06 May 2020

\begin{abstract}
Industry 4.0 demands specific conditions and resources from regions. Determining and assessing the potential of regions helps to improve the processes of decision-making of different stakeholders. This study aimed to present an approach for ranking regions. A new tool called the Regional Industrial Index (RII) was designed based on a set of 10 indicators. The RII was tested using data from regions in Bulgaria at NUTS 3 level for three years and showed the leading role of the capital region. Similar studies conducted in other countries of the EU and the Balkan states can be used for a comparative perspective. The research contributes to the scientific and practical discourse in the decision-making process for choosing the most relevant regions for developing Industry 4.0.
\end{abstract}

Keywords: regional potential, regional development, regional analysis, regional comparison, industry 4.0, industrial transformation.

JEL Classification: O14, O18, P25, R12, R58.

\section{Introduction}

The development of new generations of digital technologies is being identified as a leading factor and foundation for building a competitive national economy in the coming decades. The impact of the implementation of digital technologies in the manufacturing sector, in particular, is a strategic priority at the global and European Union levels.

In 2017, the Bulgarian Government adopted the Concept for Digital Transformation of Bulgarian Industry (Industry 4.0) with three areas of intervention: (1) strengthening the link between science and industry in the country and accelerated integration of Bulgaria into European and international programs, into initiatives and networks related to the development and implementation of Industry 4.0; (2) technological renovation of the Bulgarian economy through the introduction of standards, building of infrastructure, development of specific mechanisms to stimulate the development and market introduction of technological innovations (new products, services, and production processes) through the technologies from Industry 4.0; and (3) building the human, scientific, organizational and institutional capacity for the development of Industry 4.0 in Bulgaria (Ministry of Economy Republic of Bulgaria, 2017). One of the concept's progress evaluation indicators is the number of high-tech enterprises established in partnership with leading foreign companies.

The enterprise location is a key factor in the decision-making process, determining the success of investments. There are many ranking lists at the global level such as Doing Business developed by the World Bank Group, The IMD World Competitiveness Ranking, The IMD World Digital Competitiveness Ranking, The IMD World Talent Ranking developed by the International Institute for Management Development (IMD), Global Competitiveness Index 4.0 developed by the World Economic Forum, etc. All they provide proper information by country, but entrepreneurs and investors of Industry 4.0 are facing the lack of similar information about the regions in a particular country.

Although Bulgaria is one of the regional leaders among the Balkan countries in the Global Competitiveness Index 4.0 2019 Rankings (Schwab, 2019), where Bulgaria takes $49^{\text {th }}$ place after Slovenia, which occupies $35^{\text {th }}$ place before Romania, which is in $51^{\text {st }}$ place, Greece $-59^{\text {th }}$, Turkey $-61^{\text {st }}$, Croatia $-63^{\text {rd }}$, Serbia $-72^{\text {nd }}$, Montenegro $-73^{\text {rd }}$, Albania $-81^{\text {st}}$, North Macedonia $82^{\text {nd }}$ and Bosnia and Herzegovina $-92^{\text {nd }}$ (Concept for Digital Transformation of Bulgarian Industry (Industry 4.0), 2017), the regions in Bulgaria are facing many challenges for developing Industry 4.0 such as providing conditions suitable for the 
new reality of digital transformation, globalization and strong competition between economies and regions.

This study aimed to design a tool for determining and assessing the regional potential for the development of Industry 4.0.

The object of research was regions at level NUTS 3 according to the Eurostat classification, and the conditions at the regional level for developing Industry 4.0.

A new tool called the Regional Industrial Index (RII) was designed using 10 indicators: economic activity rate, the relative share of the population aged between 25 and 64 years with higher education, foreign direct investment in nonfinancial enterprises, expenditure on acquisition of tangible fixed assets, the relative share of mediumsized enterprises in the total number of enterprises in the region, the relative share of large enterprises in the total number of enterprises in the region, expenditure on research and development, staff engaged in research and development, the relative share of individuals aged 16-74, regularly using the internet, and gross value added in industry. All indicators in the RII had equal relative weight.

The data for calculation of the RII was obtained from the National Statistical Institute. The study period was 2016-2018.

The grouping and visualization of regions by their potential for the development of Industry 4.0 were done by using GIS technologies of MapInfo ( ) Pro 2014. Microsoft $\left({ }^{\circledR}\right.$ Excel ${ }^{\circledR} 2016$ was used for the calculations.

\section{Literature review}

Industry 4.0 is a concept for the next stage of product development and it is defined as "a significant transformation of the entire industrial production by merging digital and internet technologies to conventional industry" (Stăncioiu, 2017). The fundamental concept of Industry 4.0 includes a smart factory (smart manufacturing, intelligent factory, factory of the future), new systems in the development of products and services, self-organization, smart product, new systems in distribution and procurement, adaptation to human needs, cyber-physical systems, smart city and digital sustainability (Roblek et al., 2016). Industry 4.0 aims 'to construct an open, smart manufacturing platform for industrial-networked information applications' and it is linked to a variety of technologies: horizontal and vertical system integration; the Internet of Things; cybersecurity; the cloud; big data analytics; robots; augmented reality; additive man- ufacturing (3D printing); simulation, etc. (Bahrin et al., 2016). A detailed study of Industry 4.0 concept has presented by Piccarozzi, Aquilani, and Gatti (2018), Roblek et al. (2016), Rojko (2017), Santos, Mehrsai, Barros, Araújo, and Ares (2017).

The opportunities and perspectives of sustainable macro and micro-manufacturing in the conditions of Industry 4.0 have been summarized by Stock and Seliger (2016). Kaivo-Oja, Knudsen, and Lauraéus (2018) have found that "the idea that Industry 4.0 will underpin new patterns of production and new patterns of locations can therefore not easily be discarded". Nwaiwu, Duduci, Chromjakova, and Otekhile (2020) have investigated factors that have the most impact in influencing the achievement of a sustainable process management model in the implementation of Industry 4.0 concepts within the Czech SMEs manufacturing sector and they have found that "still few of SMEs have been able to fully attain Industry 4.0 standards". The influence of factors such as the internal system of education, knowledge management, and development, the level of external partnerships in education and knowledge acquisition, availability of technologies and knowledge to develop new products/services, etc., on the business and technology transformation in the context of Industry 4.0 in Slovak, German, Austrian, Czech and Switzerland economies has been studied by Kohnová, Papula, and Salajová (2019). Mohelska and Sokolova (2018) have examined the level of organizational culture in the Czech Republic, looking for appropriate managerial approaches to the development of an organizational culture that can support the environment for innovation in the organization and facilitating entrepreneurship in the Industry 4.0 concept. Magruk (2016) has analyzed different dimensions of uncertainty regarding Industry 4.0, both in terms of opportunities and threats, and identifies potential areas requiring research to minimize negative effects.

Papers related to the research aim present results focused on the readiness of businesses for Industry 4.0 (Ślusarczyk, 2018); the readiness of cities for Industry 4.0 (Nick \& Pongrácz, 2016); Industry 4.0 and competitiveness (Bal \& Erkan, 2019); industrial competitiveness of the Baltic States (Remeikiene et al., 2015), new trends of development of beer industry in Lithuania (Petraškevičius \& Nedelko, 2017), factors which limit the application of Building Information Modelling in the construction industry (Sun et al., 2017); smart factory performance and Industry 4.0 (Büchi et al., 2020); Industry 4.0 learning factory for regional SMEs (Faller \& Feldmüller, 2015); challenges of 
Industry 4.0 for small and medium-sized enterprises (Schröder, 2016); identification of the factors that affect the introduction of Industry 4.0 elements to small and medium-sized enterprises (SMEs) (Vrchota et al., 2019); the main economic factors of sustainable manufacturing within the industrial policy concept of Industry 4.0 (Frolov et al., 2017); a conceptual approach to introduce an integrated model improving SMEs e-business technologies (Neykova \& Miltchev, 2019); technology challenges of sustainable business performance (Haseeb et al., 2019); service innovation and smart analytics for Industry 4.0 and big data environment (Lee et al., 2014); the Industry 4.0 revolution and the future of Manufacturing Execution Systems (MES) (Almada-Lobo, 2015).

The literature review showed that: there are analyses on the link between Industry 4.0 and territorial units, but no papers for the regions in Bulgaria were found; Industry 4.0 requires significant investments into modern equipment and technologies, highly-qualified labor force and people with good knowledge of information and communication technologies; it is necessary to design a tool which determines the regional potential for the development of Industry 4.0.

\section{Methods}

The specific needs of Industry 4.0 presuppose selecting a set of indicators which, from one hand, assess the socio-economic conditions of regions required by enterprises, and, on the other hand, are important and significant. The approach that was applied in the present study made use of open data published by a reliable source. The source of data was the National Statistical Institute of Bulgaria.

The indicators, collected by the National Statistical Institute, showed a variety of indicators in section Regional Statistics and Indicators for Monitoring (National Statistical Institute of Republic of Bulgaria, 2020). Ten indicators were selected as the most important, significant and relevant indicators for Industry 4.0 from a total of 45 available ones (Table 1).

This set of indicators assesses regions by conditions of the labour market, investments, structure of non-financial enterprises' market, research and development (R\&D), information society.

The labor market is a key factor in economic development, including of Industry 4.0. In the RII, it was evaluated by two indicators - economic activity rate and the relative share of the population aged between 25 and 64 with higher education. The economic activity rate is the ratio between the economically active population and the total population of the same age. The relative share of the population aged between 25 and 64 with higher education is the ratio between the population aged between 25 and 64 with higher education and the total population in the same age group. The high values of these indicators show a higher potential of a region to provide a working force and a larger selection of highly-educated labor force.

Table 1. Indicators used for the design of the Regional Industrial Index (RII)

\begin{tabular}{|l|l|}
\hline \multicolumn{1}{|c|}{ Name } & Measure \\
\hline $\begin{array}{l}\text { Economic activity rate }-15-64 \text { complet- } \\
\text { ed years }\end{array}$ & $\%$ \\
\hline $\begin{array}{l}\text { The relative share of the population aged } \\
\text { between 25 and 64 with higher education }\end{array}$ & $\%$ \\
\hline $\begin{array}{l}\text { Foreign direct investment in non- } \\
\text { financial enterprises as of 31.12. }\end{array}$ & thousand \\
\hline $\begin{array}{l}\text { Expenditure on acquisition of tangible } \\
\text { fixed assets }\end{array}$ & thousand \\
\hline $\begin{array}{l}\text { The relative share of enterprises with 50- } \\
\text { 249 employees in the total number of } \\
\text { enterprises in the region }\end{array}$ & $\%$ \\
\hline $\begin{array}{l}\text { The relative share of enterprises with } \\
\text { more than 250 employees in the total } \\
\text { number of enterprises in the region }\end{array}$ & $\%$ \\
\hline $\begin{array}{l}\text { Expenditure on research and develop- } \\
\text { ment (R\&D) }\end{array}$ & thousand \\
\hline $\begin{array}{l}\text { Staff engaged in research and develop- } \\
\text { ment (R\&D) }\end{array}$ & number \\
\hline $\begin{array}{l}\text { The relative share of individuals aged } \\
\text { 16-74, regularly using the internet }\end{array}$ & $\%$ \\
\hline Gross Value Added (GVA) in Industry & million \\
\hline
\end{tabular}

Another significant factor of Industry 4.0 development is the level of investments, which was included in the RII by two indicators - foreign direct investment in non-financial enterprises and expenditure on acquisition of tangible fixed assets. Foreign direct investment is an investment which can be the initial transaction establishing the relationship between the investor and the enterprise or subsequent transactions between them, and which involves long-term relationship concerning, to a significant degree, the influence of a foreign enterprise on the management of an enterprise resident in the national economy. Expenditure on acquisition of tangible fixed assets are different types such as land purchase and building construction, construction equipment and mechanisms purchased or manufactured by the company itself for delivery 
and installation of tangible fixed assets, for machinery, equipment, and means of transport, etc. The high values of these indicators show the investment "climate" in the region and the levels of asset recovery.

The structure of non-financial enterprises' market in regions is assessed in the RII by two indicators - the relative share of enterprises with 50 249 employees in the total number of enterprises in the region and relative share of enterprises with more than 250 employees in the total number of enterprises in the region. the relative share of enterprises with 50-249 employees in the total number of enterprises in the region is the ratio between the number of medium-sized enterprises, enterprises with 50 to 249 employees, and the total number of enterprises in the region. The relative share of enterprises with more than 250 employees in the total number of enterprises in the region is the ratio between the number of large enterprises, enterprises with more than 250 employees, and the total number of enterprises in the region. These two indicators were included in the RII to evaluate regions' structure of non-financial enterprises' market and its suitability for Industry 4.0 development. The high value of the indicators shows a region where medium-sized and large enterprises have good conditions for development.

The development of Industry 4.0 is unthinkable without R\&D. The RII includes two indicators for assessing the level of $R \& D$ in each region expenditure on $R \& D$ and staff engaged in $R \& D$. Research and development activity comprises creative work activities focused on increasing the knowledge of mankind, culture, and society. $E x$ penditure on $R \& D$ is composed of capital expenditure on $\mathrm{R} \& \mathrm{D}$ and current costs such as labor costs, expenditure on materials, external services and other current costs, supporting R\&D activity. Staff engaged in $R \& D$ comprises researchers and other R\&D personnel and shows the human resources responsible for the creation, application, and dissemination of new knowledge. The regions with high values of these indicators have relative advantages to attract Industry 4.0 on their territory.

The relative share of individuals aged 16-74, regularly using the internet is an indicator measuring the level of information society at a regional level. It is a ratio between individuals aged between 25 and 74 using the internet every day or at least once per week, and the total population in the same age group. The high value of the indicator is a precondition for the successful development of Industry 4.0.
Gross Value Added (GVA) in Industry gives a general characterization of the economy in each region and it equals gross output less intermediate consumption of a region. The high value of GVA in Industry describes regions with a working industrial sector and good possibilities for the development of Industry 4.0.

The Regional Industrial Index (RII) was calculated in three steps.

In the first step, all indicators were normalized to avoid the problem with different measuring scales: five of the indicators in the RII are measured in percentages, four use a monetary unit, one has an absolute value (number).

The normalization of indicators was done by STANDARDIZE - a function in Microsoft ${ }^{\circledR}$ Excel ${ }^{\circledR} 2016$. The syntax of the function is

STANDARDIZE(x, mean, standard_dev),

where $x$ is the value of indicator; mean - the arithmetic mean of the indicator calculated by values for all regions; standard_dev - the standard deviation of the indicator calculated by values for all regions.

The arithmetic mean of the indicator was calculated by AVERAGE - a function in Microsoft ${ }^{\circledR}$ Excel ${ }^{\circledR} 2016$. The syntax of the function is

AVERAGE(number 1 , number $2, \ldots$ ),

where numberl, number $2, \ldots$ are the values of an indicator for each region.

The standard deviation of the indicator was calculated by STDEV.P - a function in Microsoft ${ }^{\circledR}$ Excel ${ }^{\circledR}$ 2016. The syntax of the function is

STDEV.P(number1, number $2, \ldots)$,

where numberl, number $2, \ldots$ are the values of an indicator for each region.

In the second step, a hypothetical region, called the standard region, as defined by the best normalized values of the indicators used.

In the third step, the RII for each region was calculated by formula 4 where all indicators had equal relative weight.

$$
R I I_{i}=\sqrt{\sum_{j=1}^{m}\left(z_{i j}-z_{s j}\right)^{2}}
$$

where $R I I_{j}$ is the Regional Industrial Index (RII) for the $i^{\text {th }}$ region; $z_{i j}$ - the normalized value of the $j^{\text {th }}$ indicator for the $i^{\text {th }}$ region; $z_{s j}$ - the normalized value of $j^{\text {th }}$ indicator for the standard region; $m-$ the number of indicators. 
The RII presents the distance of the studied regions from the standard region. The regions which are the most suitable for Industry 4.0 development have the lowest RII scores, which means they are the closest to the standard region. The regions which are less suitable for Industry 4.0 development have higher RII scores, which means they are farther from the standard region.

\section{Object of research}

The Regional Industry Index (RII) was calculated using data about regions in Bulgaria at the NUTS 3 level. The choice was based on rational criteria: the regions at NUTS 1 or NUTS 2 levels give a very general view of the conditions for Industry 4.0 development at these territorial levels, the territorial units at LAU 1 or LAU 2 levels present special cases which are linked with the analysis aiming at a particular production. NUTS and LAU are abbreviations used by Eurostat for statistical data and socioeconomic analyses of territorial units in the European Union and stand for Statistical Classification of Territorial Units (NUTS) and Local Administrative Unit (LAU) (Regulation (EC) No 1059/2003, 2003).

The regions at NUTS 3 level in Bulgaria are 28. They include the territory of several neighboring municipalities. They have an administrative center whose name is the name of the region. The county's capital is a separate region but it is the administrative center of 2 regions. According to the Constitution of the Republic of Bulgaria, a region is an administrative-territorial unit for conducting regional policy, for implementing state governance at a local level and ensuring the concurrence of national and local interests (Constitution of the Republic of Bulgaria, 1991, Art. 142). The regional governor, appointed by the Council of Ministers, governs each region, ensures the implementation of the State's policy, safeguards the national interests, law and public order, and exercises administrative control (Constitution of the Republic of Bulgaria, 1991, Art. 143).

\section{Results and discussions}

The results of the proposed method and the indicator set for determining the regional potential for the development of Industry 4.0 are presented in Table 2.

The results show that the best conditions for the development of Industry 4.0 in 2018 were in Sofia (capital). This fact was not unexpected because the capital of Bulgaria has a leading position in most indicators. Sofia (capital) was not the leader only in the field of the structure of the non- financial enterprises' market. The area of the region is a limiting factor for medium-sized and large enterprises to do business in it.

In the easiest analysis of the RII 2018 score and the RII 2018 ranking list, the regions, except for the leading region, were divided into 3 groups with an equal number of units. They were conventionally called - Regions with high potential for the development of Industry 4.0, Regions with moderate potential for the development of Industry 4.0 and Regions with low potential for the development of Industry 4.0 (Figure 1).

Table 2. The Regional Industrial Index (RII) Score for the 2018 year by NUTS 3 level regions in Bulgaria

\begin{tabular}{|c|c|c|c|}
\hline \multicolumn{2}{|c|}{ Region } & \multirow{2}{*}{$\begin{array}{c}\text { RII } 2018 \\
\text { Score }\end{array}$} & \multirow{2}{*}{$\begin{array}{c}\text { RII } 2018 \\
\text { Rank }\end{array}$} \\
\hline Code 2021* & Name & & \\
\hline BG311 & Vidin & 12.758 & 18 \\
\hline BG312 & Montana & 13.476 & 28 \\
\hline BG313 & Vratsa & 12.774 & 19 \\
\hline BG314 & Pleven & 12.526 & 14 \\
\hline BG315 & Lovech & 12.485 & 12 \\
\hline BG321 & \begin{tabular}{|l|} 
Veliko \\
Tarnovo
\end{tabular} & 11.744 & 7 \\
\hline BG322 & Gabrovo & 11.707 & 6 \\
\hline BG323 & Ruse & 11.484 & 5 \\
\hline BG324 & Razgrad & 13.212 & 26 \\
\hline BG325 & Silistra & 13.018 & 22 \\
\hline BG331 & Varna & 10.864 & 3 \\
\hline BG332 & Dobrich & 13.067 & 23 \\
\hline BG333 & Shumen & 12.026 & 8 \\
\hline BG334 & Targovishte & 12.608 & 15 \\
\hline BG341 & Burgas & 12.116 & 9 \\
\hline BG342 & Sliven & 12.816 & 20 \\
\hline BG343 & Yambol & 13.089 & 25 \\
\hline BG344 & Stara Zagora & 11.188 & 4 \\
\hline BG411 & Sofia (capital) & 2.158 & 1 \\
\hline BG412 & Sofia & 12.492 & 13 \\
\hline BG413 & Blagoevgrad & 12.674 & 17 \\
\hline BG414 & Pernik & 12.255 & 11 \\
\hline BG415 & Kyustendil & 13.326 & 27 \\
\hline BG421 & Plovdiv & 9.966 & 2 \\
\hline BG422 & Haskovo & 13.070 & 24 \\
\hline BG423 & Pazardzhik & 12.667 & 16 \\
\hline BG424 & Smolyan & 12.168 & 10 \\
\hline BG425 & Kardzhali & 12.894 & 21 \\
\hline
\end{tabular}




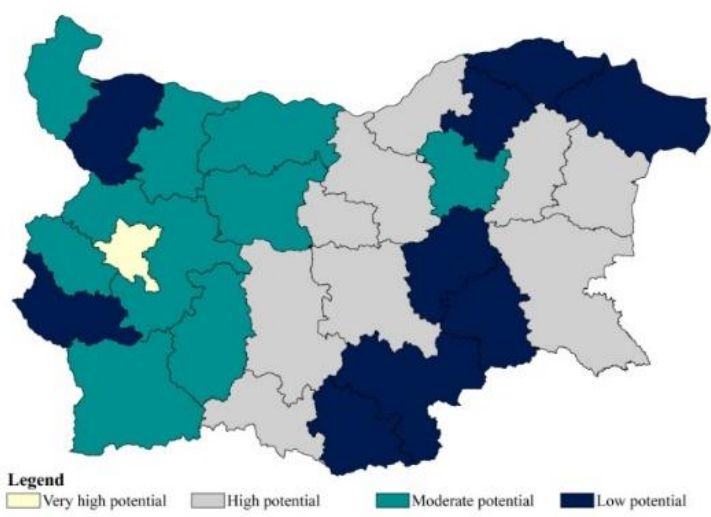

Figure 1. The Regional Industrial Index 2018 of NUTS 3 regions in Bulgaria

The regions with high potential for the development of Industry 4.0 in 2018 were the major cities of Bulgaria - Plovdiv ( $2^{\text {nd }}$ large city by population), Stara Zagora ( $6^{\text {th }}$ large city by population) and Shumen $\left(10^{\text {th }}\right.$ large city by population $)$; the Black sea ports - Varna ( $3^{\text {rd }}$ large city by population) and Burgas (4 $4^{\text {th }}$ large city by population); the Danube river port - Ruse $\left(5^{\text {th }}\right.$ large city by population); the medium-sized cities - Veliko Tarnovo (14 ${ }^{\text {th }}$ large city by population), Gabrovo (18 ${ }^{\text {th }}$ large city by population) and Smolyan (32 ${ }^{\text {nd }}$ large city by population). The in-depth analysis of the mediumsized cities showed that they are old industrial centers (Gabrovo, Veliko Tarnovo) or they are close to the well-developed industrial regions (Smolyan). The group of regions with moderate potential for the development of Industry 4.0 in 2018 included mainly regions from western Bulgaria. The economic conditions in these regions are deeply affected by the region of Sofia (capital), their geography location between the leading region and the regions with high potential for the development of Industry 4.0 and their location on the corridors Orient/East-Med and Rhine-Danube of the TransEuropean Transport Network (TEN-t) (Regulation (EU) No 1316/2013). The regions with low potential for the development of Industry 4.0 in 2018 were border regions ( 6 regions from a total of 9 belong to the group) and mountainous regions ( 2 regions from a total of 9 belong to the group). What they have in common was: depopulation; an unfavorable structure of the population; an unfavorable educational structure of the population; a high relative share of municipalities defined as rural regions, etc.

The dynamics of the conditions for Industry 4.0 development was studied by calculating the RII for 2016 and 2017. It was found out that no region changed its group (Figure 2). There were fluctuations of regions within the group, but the changes in the observed indicators were insignificant or had the same relative proportion and size that did not cause substantial rearrangement in the ranking lists.

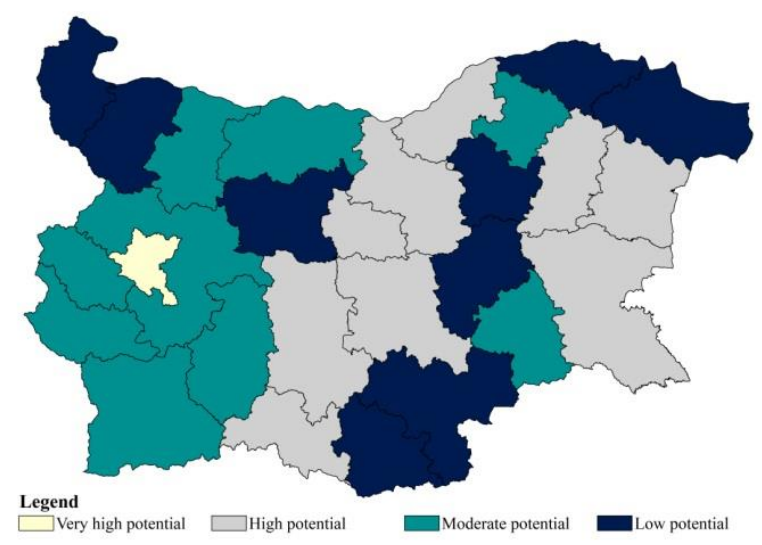

a)

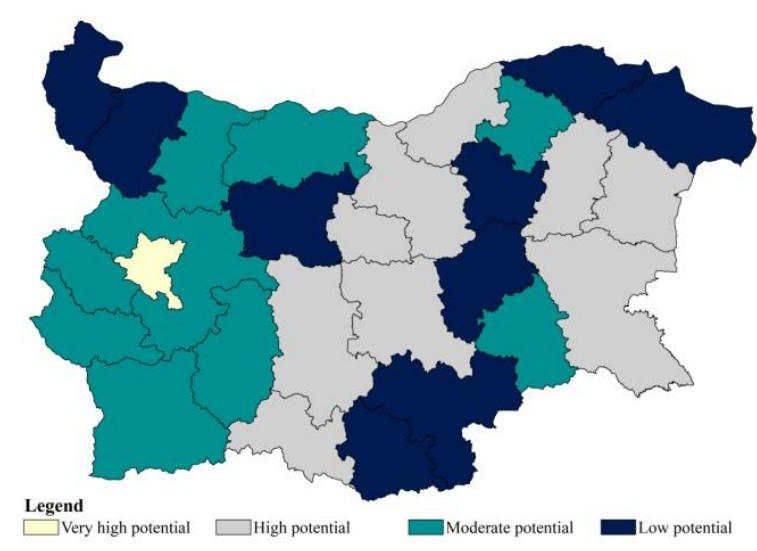

b)

Figure 2. The Regional Industrial Index of NUTS 3 regions in Bulgaria: a) 2016 year; b) 2017 year

The analysis of the RII ranks showed that more ranks' changes occurred in 2017 in comparison to 2016. For this period it was observed that the same number (eleven) regions changed their places in the RII ranking list (Figure 3a). These were mainly regions with moderate or low potential for the development of Industry $4.0-21$ regions of a total of 22 regions. The only exception was Razgrad, a region with moderate potential for the development of Industry 4.0 in the RII 2016 ranking list. The other 6 regions did not change their place in the RII ranking lists for the study period -5 of them were regions with high potential of development of Industry 4.0.

The last region that did not change its place in the RII ranking list was the leading region, the region with very high potential for the development 
of Industry 4.0, i.e. Sofia (capital). This fact was also observed in the next period when analyzing the changes in the RII 2017 and the RII 2018 ranking lists (Figure 3b). It was observed that the number of regions that did not change their place in the RII ranking lists was higher in comparison to the previous period. They were 10 in 2018/2017 compared to 6 in 2017/2016. Again, these were regions with very high or high potential for the development of Industry 4.0. The ratio between the regions which moved up in the RII ranking list and the regions which moved down in the RII ranking list was the same, meaning the changes in the conditions for Industry 4.0 development were insignificant or had the same relative proportion and size.

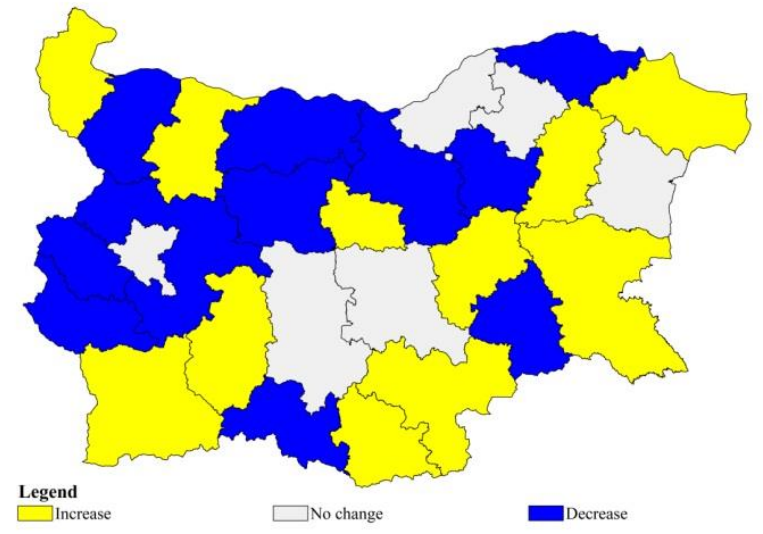

a)

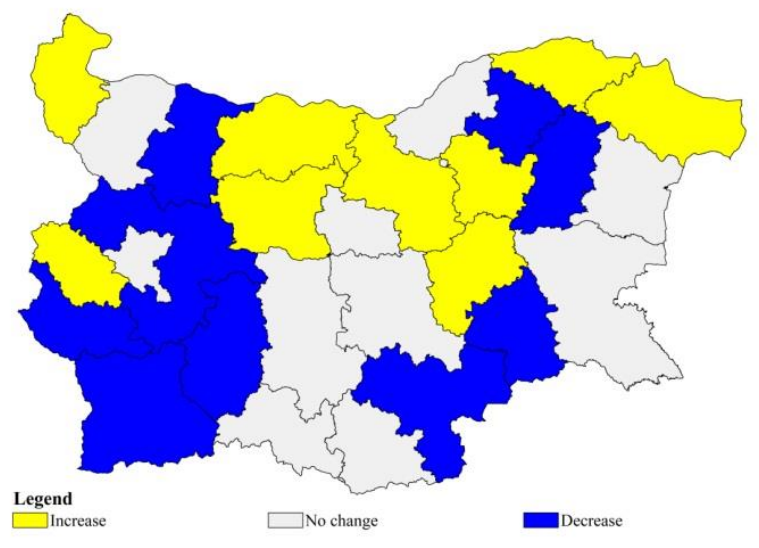

b)

Figure 3. Changes in places of the regions in the Regional Industrial Index:

a) $2017 / 2016$; b) $2018 / 2017$

The RII ranks and the RII score for the study period from 2016 till 2017 showed undoubted and clear region-leader where conditions for the development of Industry 4.0 reply to the high and specific requirements of this business. This region is the capital of the country - Sofia. The second region in the RRI ranking lists was Plovdiv - the second city in the county by population, but careful and unprejudiced analysis showed not an optimis- tic picture. The difference between the first and the second region by the RII score was 4.62 times in 2018 , and the difference between the first and the third region by the RII score was 5.03 times in the same year. The standard deviation between the other regions with places from 4 to 28 in the RII 2018 ranking list was 0.5768 which means the division of the region into three groups was a little bit by condition for a more easer understanding of the approach and the results. The small differences between regions except the Top 3 are not a sign that the conditions in regions for the development of Industry 4.0 are the same and only major cities are suitable for it. Examples for this are Gabrovo, Veliko Tarnovo, Shumen.

\section{Conclusions and recommendations}

The results of the Regional Industrial Index (RII) ranking lists for the 2016-2018 year showed that Sofia (capital) had the highest potential and the best conditions for the development of Industry 4.0. The next in the RRI rating lists were the major cities (Plovdiv, Varna, Burgas, Ruse and Stara Zagora) and cities with traditions in industrial production (Gabrovo and Veliko Tarnovo). But for the whole study period, it was observed that the disparities between the capital region and all other regions were significant, and the differences between all regions excluding Sofia (capital) were relatively insignificant. The gap in the RII score between the leading region and other regions in practice did not change for the study period. The regions with moderate or low potential for the development of Industry 4.0 generally had relatively high levels of depopulations, the unfavourable structure of the population (high relative share of the over-working-age population), unfavorable educational and qualification structure of labor force (in some regions, the greater part of the labor force is not suitable not only for Industry 4.0 but also for any industrial production), specific characteristics (some of them are the border, rural or mountainous regions).

The analysis of the newly created RII and its implementation showed that it is a workable tool for determining the regional potential for the development of industry 4.0. The set of indicators is suitable and sensitive to changes in time. A limiting factor of the proposed approach is indicator data availability.

The advantages of the method used for calculating the RII are that it allows: changing indicators in case they are not available; using unlimited numbers of indicators with different scales and with different measures; using non-professional 
software for calculations, and compiling ranking lists of studied territorial units.

The RII can be used in the decision-making process of entrepreneurs and investors, for developing regional plans and strategies by regional and local authorities, for regional comparisons. Regions, including these in Bulgaria, often face many challenges for developing Industry 4.0. One of them is providing conditions that assist the transformation of industrial production into businesses that implement and widely use the information and communications technologies (ICT). Possible actions which can solve the problem and decrease the disparities between regions are to encourage: the establishment of new enterprises and start-up companies in less attractive regions through building industrial zones, technoparks and innovative centers; lifelong learning focusing on improving the skills in information and communication technologies; improvements in the infrastructure and provision of high-speed broadband internet in all regions and towns.

Similar studies conducted in other countries of the EU, the Balkan states, the Baltic states, the economic leaders of the EU and the countries of the Visegrad Group can be used for a comparative perspective and for identifying regions with good conditions for developing Industry 4.0, regions which adopt good management practices, are open for developing and applying innovations, have fewer barriers for the digital transformation of the industry, etc.

The research contributes to the scientific and practical discourse in the decision-making process for choosing the most relevant regions for developing Industry 4.0. Besides, the conceptual model adopted in the research will benefit all stakeholders such as entrepreneurs and investors in their strategic actions and plans for developing or expanding their businesses, as well as regional and local authorities in developing regional, local and urban policies.

\section{Acknowledgements}

This research was supported by the National Science Fund of Bulgaria [No КП-06-M25/2 on December 13, 2018].

\section{References}

Almada-Lobo, F. (2015). The Industry 4.0 revolution and the future of Manufacturing Execution Systems (MES). Journal of Innovation Management, 3(4), 16-21.

https://doi.org/10.24840/2183-0606_003.004_0003
Bahrin, M. A. K., Othman, M. F., Azli, N. N., \& Talib, M. F. (2016). Industry 4.0: A review on industrial automation and robotic. Jurnal Teknologi, 78(6-13), 137-143. https://doi.org/10.11113/jt.v78.9285

Bal, H. Ç., \& Erkan, Ç. (2019). Industry 4.0 and competitiveness. Procedia Computer Science, 158, 625-631. https://doi.org/10.1016/j.procs.2019.09.096

Büchi, G., Cugno, M., \& Castagnoli, R. (2020). Smart factory performance and Industry 4.0. Technological Forecasting and Social Change, 150, 119790. https://doi.org/10.1016/j.techfore.2019.119790

Constitution of the Republic of Bulgaria. (1991). State Gazette, No 56/1991.

European Parliament and of the Council. (2019). Commission Delegated Regulation 2019/1755 of 8 August 2019 amending the Annexes to Regulation (EC) No 1059/2003 on the establishment of a common classification of territorial units for statistics (NUTS). C/2019/5841 OJ L 270, 24.10.2019, p. 1-56. ELI.

http://data.europa.eu/eli/reg_del/2019/1755/oj

Faller, C., \& Feldmüller, D. (2015). Industry 4.0 learning factory for regional SMEs. Procedia CIRP, 32, 88-91.

https://doi.org/10.1016/j.procir.2015.02.117

Frolov, V. G., Kaminchenko, D. I., Kovylkin, D. Y., Alex, J., \& Alex, A. (2017). The main economic factors of sustainable manufacturing within the industrial policy concept of industry 4.0. Academy of Strategic Management Journal, 16(2).

Haseeb, M., Hussain, H. I., Ślusarczyk, B., \& Jermsittiparsert, K. (2019). Industry 4.0: A solution towards technology challenges of sustainable business performance. Social Sciences, 8(5), 154. https://doi.org/10.3390/socsci8050154

Kaivo-Oja, J., Knudsen, M. S., \& Lauraéus, T. (2018). Reimagining Finland as a manufacturing base: The nearshoring potential of Finland in an industry 4.0 perspective. Business, Management and Education, 16, 65-80. https://doi.org/10.3846/bme.2018.2480

Kohnová, L., Papula, J., \& Salajová, N. (2019). Internal factors supporting business and technological transformation in the context of Industry 4.0. Business: Theory and Practice, 20, 137-145. https://doi.org/10.3846/btp.2019.13

Lee, J., Kao, H. A., \& Yang, S. (2014). Service innovation and smart analytics for industry 4.0 and big data environment. Procedia CIRP, 16(1), 3-8. https://doi.org/10.1016/j.procir.2014.02.001

Magruk, A. (2016). Uncertainty in the sphere of the industry 4.0 - potential areas to research. Business, Management and Education, 14(2), 275-291. https://doi.org/10.3846/bme.2016.332 
Ministry of Economy Republic of Bulgaria. (2017). Concept for digital transformation of Bulgarian industry (Industry 4.0) (in Bulgarian).

https://www.mi.government.bg/bg/themes/koncepci ya-za-cifrova-transformaciya-na-balgarskataindustriya-industriya-4-0-1862-468.html

Mohelska, H., \& Sokolova, M. (2018). Management approaches for Industry 4.0 - the organizational culture perspective. Technological and Economic Development of Economy, 24(6), 2225-2240. https://doi.org/10.3846/tede.2018.6397

National Statistical Institute of Republic of Bulgaria. (2020). Regional statistics and indicators for monitoring. Retrieved January 31, 2020, from

https://www.nsi.bg/en/content/11262/regional-statistics

Neykova, M., \& Miltchev, R. (2019) Conceptual approach to introduce an integrated model improving SMEs e-business technologies. Management Theory and Studies for Rural Business and Infrastructure Development, 41(3), 381-399.

https://doi.org/10.15544/mts.2019.31

Nick, G., \& Pongrácz, F. (2016). How to measure Industry 4.0 readiness of cities. Industry 4.0, I(2), 136-140.

Nwaiwu, F., Duduci, M., Chromjakova, F., \& Otekhile, C. A. F. (2020). Industry 4.0 concepts within the Czech SME manufacturing sector: an empirical assessment of critical success factors. Business: Theory and Practice, 21(1), 58-70. https://doi.org/10.3846/btp.2020.10712

Petraškevičius, V., \& Nedelko, Z. (2017). New trends of development of the beer industry in Lithuaniadiversification and social responsibility. Business, Management and Education, 15(1), 140-157. https://doi.org/10.3846/bme.2017.367

Piccarozzi, M., Aquilani, B., \& Gatti, C. (2018). Industry 4.0 in management studies: A systematic literature review. Sustainability, 10(10), 3821. https://doi.org/10.3390/su10103821

Regulation (EC) No 1059/2003 of the European Parliament and of the Council of 26 May 2003 on the establishment of a common classification of territorial units for statistics (NUTS). OJ L 154, 21.6.2003, p. 1 ELI. http://data.europa.eu/eli/reg/2003/1059/2018-01-18

Regulation (EU) No 1316/2013 of the European Parliament and of the Council of 11 December 2013 establishing the Connecting Europe Facility, amending Regulation (EU) No 913/2010 and repealing Regulations (EC) No 680/2007 and (EC)
No 67/2010 Text with EEA relevance, OJ L 348, 20.12.2013, p. 129-171 ELI.

http://data.europa.eu/eli/reg/2013/1316/oj

Remeikiene, R., Startiene, G., \& Dumciuviene, D. (2015). Assessment of the industry competitiveness of the Baltic States in the EU during the period of economic recession. Technological and Economic Development of Economy, 21(1), 79-95. https://doi.org/10.3846/20294913.2014.994052

Roblek, V., Meško, M., \& Krapež, A. (2016). A complex view of industry 4.0. Sage Open, 6(2). https://doi.org/10.1177/2158244016653987

Rojko, A. (2017). Industry 4.0 concept: background and overview. International Journal of Interactive Mobile Technologies (IJIM), 11(5), 77-90. https://doi.org/10.3991/ijim.v11i5.7072

Santos, C., Mehrsai, A., Barros, A. C., Araújo, M., \& Ares, E. (2017). Towards Industry 4.0: an overview of European strategic roadmaps. Procedia Manufacturing, 13, 972-979.

https://doi.org/10.1016/j.promfg.2017.09.093

Schröder, C. (2016). The challenges of industry 4.0 for small and medium-sized enterprises. FriedrichEbert-Stiftung: Bonn, Germany.

Schwab, K. (Ed.) (2019). The Global Competitiveness Report 2019. The World Economic Forum. www.weforum.org/gcr

Ślusarczyk, B. (2018). Industry 4.0: Are we ready? Polish Journal of Management Studies, 17, 232 248. https://doi.org/10.17512/pjms.2018.17.1.19

Stăncioiu, A. (2017). The fourth industrial revolution "Industry 4.0". Fiability \& Durability/Fiabilitate si Durabilitate, 1(19), 74-78.

Stock, T., \& Seliger, G. (2016). Opportunities for sustainable manufacturing in industry 4.0. Procedia Cirp, 40, 536-541. https://doi.org/10.1016/j.procir.2016.01.129

Sun, C., Jiang, S., Skibniewski, M. J., Man, Q., \& Shen, L. (2017). A literature review of the factors limiting the application of BIM in the construction industry. Technological and Economic Development of Economy, 23(5), 764-779. https://doi.org/10.3846/20294913.2015.1087071

Vrchota, J., Volek, T., \& Novotná, M. (2019). Factors introducing industry 4.0 to SMEs. Social Sciences, $8(5), 130$.

https://doi.org/10.3390/socsci8050130 